\title{
EDITORIAL
}

\section{El cuerpo como inagotable reservorio del pensar, sentir, decir, hacer}

\author{
Josefina Ramírez Velázquez ${ }^{1}$ \\ Escuela Nacional de Antropología e Historia ENAH \\ Instituto Nacional de Antropología e Historia INAH \\ México \\ jos.ramirez.velazquez@gmail.com \\ DOI: https://doi.org/ 10.14483/25909398.15501
}

\begin{abstract}
1 Coordinadora de la Línea de Investigación “Cuerpo y Poder” del Posgrado de Antropología Física de la ENAH. Dra. En Antropología con especialización en Antropología Médica. Sistema Nacional de Investigadores SNI Nivel II.
\end{abstract}

La Revista Corpo-grafías como publicación de la Facultad de Artes ASAB, Universidad Distrital Francisco José de Caldas, (BogotáColombia), a cargo de la Línea de investigación en Estudios Críticos de las Corporeidades, las Sensibilidades y las Performatividades, acordó disponer el presente número para registrar algunas reflexiones y artículos de investigación que formaron parte del III Encuentro Latinoamericano de Investigadores sobre Cuerpos y Corporalidades en las Culturas titulado "Escrituras, lecturas e interpretaciones de cuerpos y corporalidades entre la ciencia y el arte", que se llevó a cabo en noviembre del 2018 en la Ciudad de México.

Dicho encuentro es uno de los eventos más trascendentales que cada tres años produce la Red de investigación de y desde los cuerpos, antes conocida como Red de antropología de y desde los cuerpos. Este notable cambio derivó en buena medida por la cada vez más amplia participación de estudiosos del cuerpo y las corporalidades desde diferentes disciplinas humanísticas, sociales y artísticas, y de aportaciones de diversas perspectivas teórico-metodológicas desde las cuales se devela de manera preponderante el interés por construir eslabones entre los procesos de teorización, la práctica artística y el activismo, poniendo en el centro del debate al cuerpo y sus condiciones materiales, existenciales, históricas, socioculturales y políticas.

Desde el I Encuentro realizado en 2012 en Rosario, Argentina, el interés antropológico de pensar el acontecer del cuerpo, llevó a Ixs impulsorxs de la Red a convocar a la reflexión colectiva en busca del mejor horizonte de explicación y comprensión que, dada su complejidad y la necesidad de evitar cualquier tipo de reduccionismo, invitó a trabajar en el diálogo entre el cuerpo y las corporalidades. Los integrantes de la Red en Argentina han producido desde entonces investigaciones diversas enfocando la corporalidad considerada como la condición existencial y fundamento intersubjetivo de la experiencia cultural (véase la amplia producción del Equipo de Antropología del Cuerpo de la UBA, coordinado por la Dra. Silvia Citro). Y han desarrollado la performance como método de investigación transdisciplinario (Citro, 2015), o espacio liminal en donde se encuentran -productivamenteinvestigadorxs y artistas interesadxs por narrar, desde otras formas de expresión, la manera en que las corporalidades, desde roles específicos (investigadxr/investigadx) y posiciones identitarias (de clase, género, grupo etario, etnia y raza) se significan, reproducen, legitiman o subvierten.

Las corporalidades titilantes se vuelven aún más fértiles en el II Encuentro realizado en 2015 en Bogotá-Colombia, con la demanda impostergable de comprender el arte y lo estético más allá de lo bello y en consecuencia revelar su capacidad de expresión política, en investigaciones críticas y rigurosas. Desde este punto de vista el activo equipo de trabajo de la Línea de investigación de Estudios Críticos de las Corporeidades, las Sensibilidades y las Performatividades con la dirección de la Dra. Sonia Castillo Ballén, alimentó el propósito de incorporar nuevas interrogantes teóricas y ejercicios prácticos con la aspiración por contar, desde la piel y en un intercambio colectivo de inter-sensibilidades, aquellas realidades obscurecidas por la opresión en cualquiera de sus manifestaciones y que dejan huella en los cuerpos. El mandato reflexivo de ello apunta a "asumir la condición corporal como contingencia política de la existencia" (Castillo, 2015, p.135). La propuesta del equipo de investigadorxs subraya las artes como rutas posibles para la indagación de lo sensible políticamente situado y definido en un contexto sociocultural específico. Destacar la importancia de las artes constituye la vuelta de tuerca que enlaza el giro argumental de la propia Red al potenciar su intereses por reflexionar, desde la dimensión epistemológica, la incorporación de diversas metodologías de investigación, docencia y divulgación que 
den cuenta de la investigación-creación que visibiliza la expresión relacional entre razón, emoción, palabra, gestualidad, movimiento corporal, teoría y práctica, que involucran activamente la corporalidad del investigador, del artista y de los participantes de las investigaciones en un juego de espejos que estimulan la imaginación para nuevas teorizaciones.

Así, el III Encuentro llega para noviembre del 2018 y desborda intereses en los tránsitos reflexivos de las ciencias al arte y de este a las ciencias, y perfila, en la gran mayoría de las participaciones, el acontecer del cuerpo desde una geografía visual, táctil, olfativa, gustativa, cenestésica, que expresa goce, creatividad, constreñimiento, reflexión, acción, silencio, dolor, sufrimiento.

El Palacio de la Escuela de Medicina, otrora espacio histórico de la Inquisición y el Santo Oficio en México, que tuvo al cuerpo sujetado y torturado como el centro de su poderío y control de las almas, es en la actualidad un ámbito destinado a la enseñanza y capacitación de médicos y enfermeros para devolver al cuerpo su naturaleza de espacio para la investigación y generación de conocimiento y no para el suplicio. Dicho Palacio configuró entonces el escenario que acogió a cientos de participantes cuyo interés fue compartir, reflexionar y discutir las coordenadas teóricas y conceptuales antes citadas con nuevos modos de experimentar y representar las indagaciones, desde los cuales, toda acción intelectual, se manifestó con y desde el cuerpo, como acto creativo que, desde mi punto de vista, reveló el pensar sintiendo y el sentir pensando de los participantes.

Como organizadora y coordinadora académica del III Encuentro observé que el cuerpo, ese inagotable reservorio del pensar, sentir, decir, hacer, fue traído de vuelta al escenario para compartir reflexiones teóricas, artísticas y estéticas, sin dejar de admitir que ese cuerpo está dinamizado por diversos contextos significantes, pero también por la clase, el género, la etnia, la edad, por citar algunos elementos identitarios de notable importancia para su explicación relacional y situada.

Permítanme ahora hablar un poco como coordinadora de la Línea de investigación Cuerpo y Poder del posgrado de Antropología Física de la ENAH en México. De cómo el cuerpo se ha convertido, por décadas, en el centro de mi interés académico-político, teniendo como principal reflexión el giro paradigmático que dentro de la antropología física ha permitido pensar las verdades incómodas que, en esta área de conocimiento, han configurado al cuerpo en clave clasificatoria;
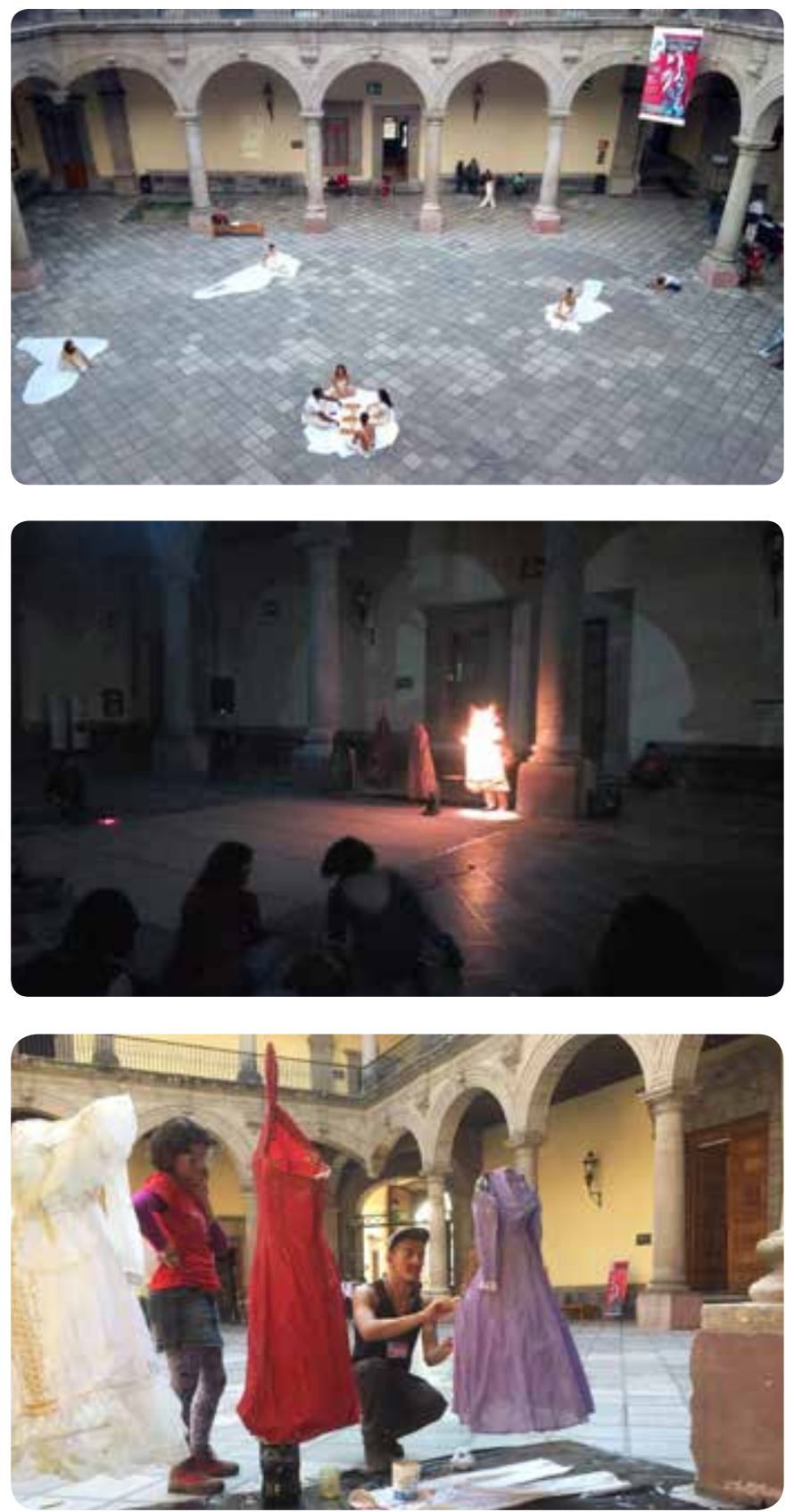

Imágenes: registro III Encuentro Latinoamericano de Investigadores sobre Cuerpos y Corporalidades en las Culturas titulado "Escrituras, lecturas e interpretaciones de cuerpos y corporalidades entre la ciencia y el arte", noviembre del 2018, Ciudad de México. Fotografías: Comité Organizador. 
como puesto por la naturaleza, universal, mesurable, para establecer diferenciación y explicar la variabilidad humana. En este sentido, el cuerpo como compendio orgánico que contiene la historia evolutiva de la humanidad requería ser deconstruido epistémicamente en un proceso de desmarque sobre aquellas verdades incómodas, dado que han servido para describir a los otros como objetos: cuerpos inferiorizados, irracionales, ignorantes, discriminados por sus dimensiones y formas corporales y por su color de pelo y piel.

Esas verdades orientaron mi quehacer intelectual que no me llevó a las corporalidades como concepto que articula otras posibilidades de comprensión, sino que me exigió un ejercicio epistémico sobre el 'cuerpo objeto' soma y organismo, que en antropología física solo aparece problematizado hasta los años noventa del siglo pasado, a través de la simple pregunta ¿de qué cuerpo hablamos? (Ramírez, 2012). Mi lectura política del cuerpo pasa en principio por la crítica hacia la retórica de verdad construida sobre el cuerpo objeto y la función del saber producido sobre este, en el que claramente se advierte la relación saber/poder que, como diría Foucault (1976), si hay un ejercicio de poder sobre el cuerpo es porque hay saberes que, a partir de sus efectos de verdad, producen efectos de poder. Pero también pasa por el reconocimiento del carácter moral de la antropología cuyo objetivo ha sido dar la voz a las subculturas, sumergidas y silenciadas, es decir aquellos cuerpos inferiorizados, los sin voz.

La búsqueda por superar esas verdades incómodas y las oposiciones binarias que las sostienen, cuerpo/mente, biología/sociedad, sujeto/ objeto, naturaleza/cultura, razón/emoción, individuo/sociedad, ha pautado mi reflexión hacia otro orden de comprensión del cuerpo y sus condiciones. De manera que, desde la antropología física crítica (Ramírez, 2010) el cuerpo se piensa como sujeto y agente al reconocer que la especie humana está conformada por hombres y mujeres que son, de manera distintiva, productores de sentido.

Pensar críticamente sobre el ejercicio de la antropología física me llevó a construir la línea de investigación Cuerpo y Poder, desde la cual, la tarea primaria fue armar una propuesta de revisión ontológica y epistémica sobre la noción de cuerpo, analizado no solo como objeto sino como sujeto de conocimiento; como espacio de construcción de identidad, de producción de significaciones, de acción y negociación; develándose como el terreno más inmediato dónde se expresan el poder, el sufrimiento y las contradicciones sociales, los procesos de racialización y etnización, así como el sitio de resistencia personal y social.

Con tales elementos articuladores he ido dándole sentido al cuerpo en otro horizonte de comprensión en el cual, este para explicarse las situaciones en las que está inmerso piensa-siente-dice-actúa al respecto (Ramírez, 2016). Es decir, es un cuerpo que no solo piensa y actúa, sino que, orientado por su pensar y sentir, actúa y gestiona la vida en sociedad y esto constituye su característica intrínseca para ser propuesto como Cuerpo Sentipensante, al que defino como "campo de experiencia perceptual, de interacciones afectivas y sensibles, por medio del cual los actores construyen su mundo e interactúan produciendo significados, metáforas, representaciones, emociones y, negociando y renegociando sus situaciones en un proceso dinámico" (Ramírez, s/f).

Derivado de estos planteamientos surgen nuevos interrogantes entre los que destaca ¿cómo el cuerpo, a través de su pensar, sentir, decir y hacer gesta sus procesos de comprensión sobre su ser y estar ya sea en la normatividad, en la contradicción o en la resistencia creativa? Cuestión que se resuelve en el terreno metodológico al ejercer el oficio etnográfico y desde una narrativa vigorosa y fluida que exprese cómo los participantes de nuestras investigaciones cuentan una historia a partir de experimentar un acontecimiento que se sedimenta en su cuerpo.

Para finalizar esta participación, quiero agradecer a las colegas que dirigen esta prestigiada revista, la invitación a colaborar como editora del presente número permitiéndome exponer a grandes rasgos la ruta que han seguido los encuentros de investigadores del cuerpo y las corporalidades en las culturas, así como mi propia visión de estas temáticas que he desarrollado en la Línea de Investigación Cuerpo y Poder, delineada anteriormente.

En cuanto a la conformación del presente número he de mencionar que los ensayos que se reúnen fueron mayoritariamente expuestos en su versión de ponencia en el III Encuentro en México y respondieron a la convocatoria que se hizo a todos los participantes, para la presentación en su versión publicable.

Los trabajos recibidos tocan diversas temáticas, de las cuales destaca el estudio y expresión de cuerpos diversos: cuerpos artistas, cuerpos disidentes, cuerpos invisibles, cuerpos excluidos, cuerpos infantiles, cuerpos transgresores, cuerpos enfermos, cuerpos en la danza, cuerpos en el deporte, cuerpos embrujados, cuerpos sometidos, cuerpos envejecidos. Así como el análisis de rasgos corporales como proyecto socioideológico y la reflexión sobre la olfacción como un sentido que comunica y da sentido.

Los artículos que presenta la revista cuyos recorridos teóricos y datos empíricos que se discuten en estos ensayos contribuirán a estimular la imaginación creativa de nuestros lectores, a partir de los siguientes autores y temáticas:

Ángela María Hoyos: Cuerpos asimétricos en movimiento. / Luis Alonso Rojas Herra: La construcción espacial del sujeto indómito. / Gustavo Adolfo Enríquez Gutiérrez, Johan Cristian Cruz-Cruz: Contornos y límites corporales del hombre medio en México (1930- 


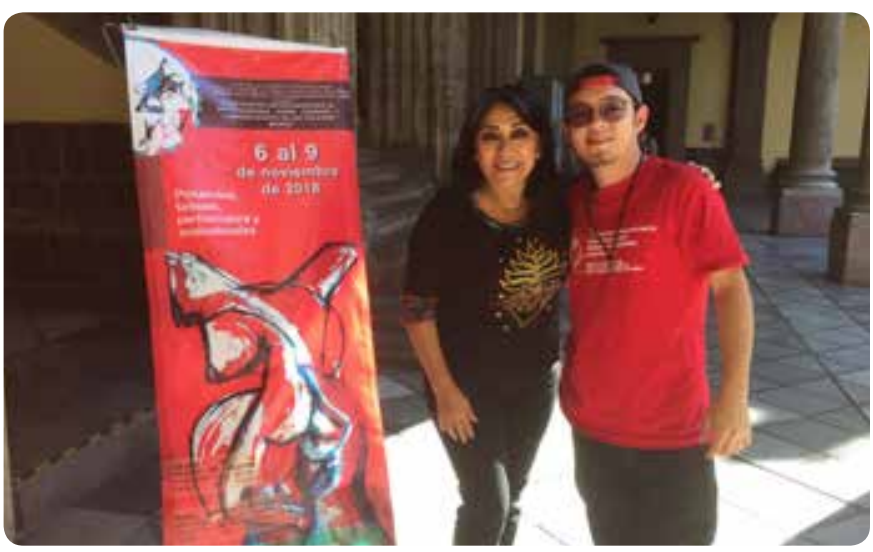

1960). / Alexandre Paulo Loro: Os corpos infantis nas instituições de acolhimento. / Aide Esmeralda López Olivares, Adelma do Socorro Gonçalves Pimentel, Lorena Schalken de Andrade: Vivencias poéticas del cuerpo: intervención artística con personas en situación de calle en Belém/PA, Brasil. / María Carmela Malaver Narváez: El cuerpo perfumado. Los aromas de la intimidad femenina en Ifigenia (Teresa de la Parra, 1924) / Laura Vázquez Vega: Cuerpos envejecidos en corporalidades rarámuri. Entre la cotidianidad y la exclusión social de un grupo étnico del norte de México. / Tomas Loza Taylor, Josefina Ramírez Velázquez: El cuerpo silenciado: Reflexiones en torno a la experiencia de personas con cáncer terminal y sus metáforas. / Minerva López Millán: Etnicidad y corporalidad en comunidades de la Huasteca Potosina: el Trazol y Dhiman talab. / Luisa Fernanda González Peña: Caleidoscopio del cuerpo: Entre imaginarios y narrativas de la diversidad corporal. / Josefina Ramírez Velázquez: La guerra en el cuerpo: Experiencia de niñas y adolescentes de la Montaña de Guerrero en un internado de religiosas en México. I Jessica Reyes Sánchez: Hacer agua de limón: aplicación del método Core Danzaterapia con personas con VIH. / Rosaura Yépez Vásquez: Las emociones del cuerpo con especial referencia a la psicosis. Lectura de una experiencia con mirada antropológica. / Jairo Gutiérrez Avendaño: Darle cuerpo a lo no patológico: estigmas de degeneración atribuidos a la locura en Colombia, finales del siglo XIX y principios del XX. / Rebeca Sánchez Aguilar: Reconfiguración del cuerpo en la danza mediada por redes telemáticas. / Javier Anzola Moreno, Aydee Robayo Torres: Relatos biográficos y experiencias encarnadas en ciclistas profesionales colombianos: tránsitos y posibilidades.

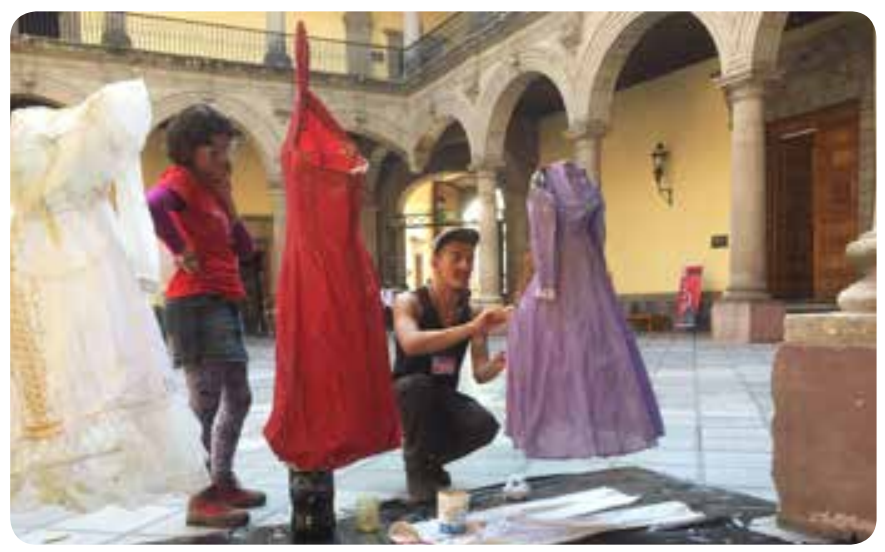

\section{Referencias}

Castillo, S. (2015). Modos de relación sintiente bocetos hacia una perspectiva del performance como ruta metodológica para la indagación de subjetividades. Cuadernos de Música, Artes Visuales y Artes Escénicas, 10(1), pp. 131-152. Doi: http:// dx.doi.org/10.11144/ Javeriana.mavae10-1.mrsb

Citro, S. (2015). Cuerpos significantes. Nuevas travesías dialécticas. Revista Corpo-grafías, Estudios críticos de y desde los Cuerpos, 1(1), pp. 10-43. Doi: https://doi.org/10.14483/cp.v1i1.8414

Foucault, M. (1976). Vigilar y castigar. (1a. Ed.). México: Siglo XXI Editores.

Ramírez, J. (2010). El desarrollo de una antropología física crítica y la generación de antropólogos físicos situados. Memorias del Primer Congreso Nacional de Antropología Social y Etnología de México. México: Rectoría de la UAM.

Ramírez, J. (2012). "Cuerpo y Emociones. Un nuevo horizonte para la comprensión del sujeto en Antropología Física". Diario de Campo, pp 22-27 México: CONACULTA/INAH.

(2016). "Las emociones como categoría analítica en antropología. Un reto epistemológico, metodológico y personal". (pp. 97-126). En Oliva López y Rocío Enríquez (Coords.), Cartografías emocionales. Las tramas de la teoría y la praxis. Colección Emociones e Interdisciplina Vol. II. México: UNAM/ ITESO.

(s/f). Una reflexión epistemológica para la construcción del cuerpo sentipensante: la búsqueda del cuerpo perdido. (Artículo inédito) México: ENAH. 